\title{
María Soledad González. Victoria Ocampo. Escritura, poder y representaciones, Rosario: Prohistoria, 2018, 181 páginas.
}

\author{
Yolanda de Paz Trueba \\ Instituto de Estudios Histórico Sociales \\ Instituto de Geografía, Historia y Ciencias \\ Sociales \\ Consejo Nacional de Investigaciones \\ Científicas y Técnicas \\ Universidad Nacional del Centro de la \\ Provincia de Buenos Aires \\ yolidepaz@gmail.com \\ (Argentina)
}

Nacida en los años finales del siglo XIX, Victoria Ocampo supo distinguirse de sus congéneres y pasar a la historia como una mujer singular. Intelectual de renombre, embajadora cultural del país, dueña de una de las editoriales más importantes del siglo $\mathrm{XX}$ fue, como afirma María Soledad González, una de las personalidades más destacadas de la cultura argentina de la centuria pasada.

No obstante eso, este libro lejos de quedarse solo en analizar la trayectoria de esta figura tan particular, pretende ir más allá y, en el cruce del género y la clase, comprender la cultura polí- tica del sector social que la vio nacer y le dio también oportunidades que otras féminas de su tiempo, no tuvieron.

Si bien la escritura era una herramienta de empoderamiento, lo cierto es que pertenecer a la elite porteña fue un aditamento nada despreciable en su carrera. Pero a diferencia de lo que una lectura rápida podría sugerir, el análisis de González subraya un punto que a mi entender, se cuenta entre los más provocadores de su trabajo: las posibilidades que le brindó a Victoria Ocampo su origen social, no fueron usadas para defender los derechos de un colectivo feminista, sino más bien en primer lugar sus propias posiciones de poder; en segunda instancia, las de su clase de pertenencia, que atravesó los años ' 30 con las tensiones propias de una época de cambios. Por ello, afirma la autora "(...) no sostenemos la ilusión de un sujeto integralmente coherente, pero tampoco podemos desconocer la presencia de un discurso que se adapta a los patrones de lo admitido $\mathrm{y}$ a las premisas fundamentales de un liberalismo fuertemente conservador." (González, 2018, p. 35). 
Así, al entender a Victoria como mujer, intelectual, pero especialmente miembro de la clase alta argentina, González logra mostrarnos a la mujer sin caer en la ilusión de ponerla en el lugar de alguien que peleó por los derechos de sus congéneres, sino los de la misma clase que la constriñó al tiempo que le dio alas.

A pesar de su participación (o quizá por su causa) en la Unión Argentina de Mujeres y su lucha por ser considerada parte en un mundo predominantemente masculino, Victoria Ocampo consideraba injusto ser mujer, por las posibilidades que se le cerraban por ello. Pero tal como afirma la autora, paradójicamente, no persiguió la reivindicación del lugar legítimo para la mujer en lo público, porque no se rebeló contra las jerarquías de género en este sentido. Tal es así que en sus escritos resaltaba el lugar de sus antepasados varones y se relacionó, como parte de su actividad cultural, con intelectuales reconocidos priorizando en esos vínculos a los de sexo masculino. Unas redes en las que no reclamó su lugar en tanto mujer, sino que buscó ponerse en el centro de una elite inmersa en un proceso turbulento. Por todo ello, González sostiene como hipótesis que el rol que ella fue asumiendo como difusora cultural se centraba en su propia persona.

Figura controvertida en su tiempo, Victoria Ocampo ha habilitado también diversas lecturas de la historiografía sobre su carrera y su vida. El libro que el lector tiene en sus manos es una interpretación sobre alguien singular en su propio tiempo, que nos la muestra asimismo fiel a las identidades de su clase y menos rupturista de lo imaginado. En virtud de esto, Victoria creía que la elite debía estar donde el Estado estaba ausente. Por ello, como las páginas comentadas muestran, el peronismo para ella representaba la barbarie y sus hombres y mujeres, eran pensados como simples advenedizos en el poder. Entendía que el peronismo subvertía el orden y contra eso se reveló.

A través de Victoria, en el análisis que el libro ofrece se entrecruzan la clase, el género (que no busca ser reivindicado sino más bien vivir a pesar él) y una búsqueda de la conservación del poder en el marco de un nuevo tiempo cultural que debió ser compartido con otros protagonistas. Pero, si bien como plantea la autora desde las primeras páginas, no se trata de un personaje que pueda ser analizado con cierta congruencia por las contradicciones que ella misma encierra, hay una línea en su trayectoria que parece estar presente a lo largo de toda su vida. Aunque en algún momento las acciones de Victoria favorecieron la lucha por los derechos civiles de las mujeres, las que además ayudaron a visibilizar ciertos combates por los derechos políticos femeninos, González logra con su enfoque poner en evidencia que Victoria Ocampo pensó la ciudadanía desde una perspectiva elitista y restringida, al tiempo que su identidad de género quedó subsumida en su filiación de clase. A tal punto habría sido así, que se opuso al voto femenino defendido por el peronismo y a la misma Eva Duarte. Postura política que la llevó a desconocerla por entenderla como una feminista de segunda línea. Tal como había intentado en su momento posicionarse como miembro de una elite heredera de los patricios y constructores del país ante los advenedizos, en relación a la defensa de los derechos femeninos oponía a las feministas de la primera hora, las genuinas, con las que adherían al peronismo.

Por todo lo dicho, sostiene la autora que más que una lucha feminista, en ella se encarnó una cultura política, dado que "No hay en sus postulados un cuestionamiento profundo al varón 
libre racional como sujeto político ni tampoco al patriarcado. El liberal conservadurismo permea como un fenómeno estructurante toda su cosmovisión” (González 2018, 140).

En síntesis, el análisis que González ofrece en este libro de la figura de Victoria Ocampo nos la presenta primero como una mujer que pese a los encorsetamientos de su época, pudo y supo destacarse en el campo cultual. Pero un rasgo permanente en su actuación intelectual no habría sido su defensa de las mujeres como colectivo, sino su pertenencia a una elite en pleno cambio. No fue en suma la reivindicación de su género lo que la habría llevado a lugares destacados, sino la de su clase y su propia persona. Fue una lucha por el poder al que la condujo su propio ego. En definitiva, dice González, el rol de Victoria fue continuador de su clase a tal punto que ya en los años '70, la dictadura la enarboló como modelo de mujer.

Vida singular la de Ocampo, interpretación arriesgada la de González que, como afirma Valeria Pita en el prólogo del libro, augura lecturas que seguramente no se verán libradas de “...apasionamientos y querellas de sentidos". Por ello mismo, invitamos al lector a sumergirse en ella.

\author{
$\approx \ddot{\bullet} \propto$ \\ Recibido: 22-04-2019 \\ Aceptado: 22-06-2019 \\ Publicado: 04-12-2019
}

